\title{
Reprodução de minhocas em substratos orgânicos e a percepção de agricultores familiares sobre a minhocultura ${ }^{1}$
}

\author{
José Ray Martins Farias ${ }^{2}$, Regiane Farias Batista ${ }^{3}$, Paulo Cesar Batista de Farias ${ }^{4}$, Adriana de Fátima \\ Meira Vital ${ }^{5}$, Rivaldo Vital dos Santos ${ }^{6}$
}

\begin{abstract}
Resumo: A pesquisa objetivou avaliar a reprodução de minhocas Eisenia foetida, em diferentes substratos e o entendimento dos agricultores familiares de três comunidades rurais do Município de Coxixola, estado da Paraíba, Brasil, sobre a vermicompostagem. O experimento foi conduzido em duas etapas: estudo de percepção com os agricultores e ensaio de campo, montado na fazenda experimental do CDSA/UFCG campus Sumé-PB, para testar a eficiência de diferentes substratos para reprodução das minhocas. O experimento foi montado nos meses de março a maio de 2017, com o delineamento experimental inteiramente casualisado, utilizando 5 tratamentos: estercos bovino (EB), ovino (EO) e caprino (EC) curtidos por um período de quinze dias, composto orgânico (CO) e a mistura proporcional dessas quatro fontes orgânicas (MIX); em 4 repetições, totalizando 20 unidades experimentais. Após 60 dias da instalação do experimento, avaliaram-se o número de indivíduos jovens e adultos, o número de casulos, o comprimento, a biomassa de todos os indivíduos e o índice de multiplicação das minhocas. Aos 60 dias de criação, a E. foetida teve taxa de reprodução significativa, sendo que os tratamentos Mix e esterco bovino apresentaram os melhores resultados para as variáveis estudadas. Quanto ao estudo da percepção dos agricultores sobre o uso de minhocas na produção agrícola, verificou-se que todos desconheciam a prática, apresentando uma visão distorcida sobre a presença destes representantes da macrofauna do solo e evidenciando a urgência da disseminação da atividade como prática de conservação do solo e geradora de renda para o povo camponês.
\end{abstract}

Palavras-chave: Vermicompostagem; Húmus; Conservação do Solo.

\section{Reproduction of mines in organic substrates and the perception of family farmers on minococulture}

\begin{abstract}
The objective of this research was to evaluate the reproduction of Eisenia foetida worms in different substrates and the understanding of the family farmers of three rural of the Municipality of Coxixola, state of Paraíba, Brazil on vermicomposting. The experiment was conducted in two stages: a perception study with the farmers and a field trial, set up at the experimental farm of the CDSA / UFCG campus Sumé-PB, to test the efficiency of different substrates for the reproduction of earthworms. The experiment was conducted from March to May 2017, with a completely randomized design, using five treatments: bovine manure (EB), sheep (EO) and goat (EC) for a period of fifteen days, organic compound ( $\mathrm{CO}$ ) and the proportional mixture of these four organic sources (MIX); in 4 replicates, totaling 20 experimental units. After 60 days of the experiment, the number of young and adult individuals, the number of cocoons, the length and the biomass of all the individuals and the multiplication index of the earthworms were evaluated. At 60 days of breeding season, E. foetida had a significant breeding rate, with Mix and cow manure treatments presenting the best results for the studied variables. Concerning the study of the farmers' perception of the use of earthworms in agricultural production, it was verified that all were not aware of the practice, presenting a distorted view on the presence of these representatives of the soil macrofauna and evidencing the urgency of the dissemination of the activity as conservation practice of the soil and generating income for the peasants.
\end{abstract}

Keywords: Vermicomposting; Humus; Soil Conservation.

\footnotetext{
${ }^{1}$ Submetido em 26/05/2018 e aprovado em 08/07/2018

${ }^{2}$ Tecnólogo em Agroecologia; Mestrando, Universidade Federal de Campina Grande (UFCG), Centro de Saúde e Tecnologia Rural, Programa de Pós Graduação em Ciência animal, Patos - Paraíba, CEP: 58700-970; E-mail: raymartinssp1 @ gmail.com

${ }^{3}$ Agroecologa; Universidade Federal de Campina Grande (UFCG), Centro de Desenvolvimento Sustentável do Semiárido, Sumé - Paraíba, CEP: 58.540-000; E-mail: regiane.2594@ gmail.com

${ }^{4}$ Engenheiro de Biossistemas; Mestrando, Universidade Federal de Campina Grande (UFCG), Centro de Saúde e Tecnologia Rural, Programa de Pós Graduação em Ciência animal, Patos - Paraíba, CEP: 58700-970; E-mail: pc.20batista@ gmail.com

${ }^{5}$ Doutora em Ciência do solo; Técnica Administrativa, Universidade Federal de Campina Grande (UFCG), Centro de Desenvolvimento Sustentável do Semiárido, Sumé - Paraíba, CEP: 58.540-000; E-mail: vital.adriana@ hotmail.com

${ }^{6}$ Doutor em Agronomia; Professor Associado IV, Universidade Federal de Campina Grande (UFCG), Centro de Desenvolvimento Sustentável do Semiárido, Sumé - Paraíba, CEP: 58.540-000; E-mail: vitalrivaldo@ gmail.com
} 


\section{Introdução}

Toda ação humana gera resíduos, sendo assim, a existência destes é algo que caminha em paralelo com as atividades dos diversos setores. A variabilidade destes rejeitos produzidos em todas as atividades das sociedades compreende resíduos que podem ser classificados de acordo com sua origem, doméstica, comercial e rural (Lago et al., 2006).

Evitar a degradação dos recursos ambientais e a contaminação do solo pela disposição inadequada do lixo é medida de urgência e a adoção de sistemas agroecológicos de produção entre os agricultores familiares é uma opção para otimização da eficiência no uso dos recursos naturais, já escassos (Mucelin e Bellini, 2008).

A utilização de resíduos orgânicos oriundos da criação de animais é uma alternativa para a fertilização de áreas agrícolas, manejando de maneira adequada os resíduos gerados pelos animais domesticados (Darolt., 2008). Além desses resíduos, o composto orgânico e o vermicomposto ou húmus de minhoca, surgem como práticas importantes para manter a fertilidade do solo, a sustentabilidade dos agroecossistemas e agregar valor à produção agrícola (Costa et al., 2011).

Este produto vermicompostado é o resultado da ação de minhocas e dos micro-organismos que habitam seus intestinos, dando origem ao húmus. Embora pouco conhecido pelos agricultores, o vermicomposto ou húmus de minhoca é, segundo Penteado (2009), um produto altamente rico em nutrientes que pode melhorar significativamente as características físicas, químicas e biológicas dos solos, permitindo não só recuperar solos degradados por práticas inadequadas, com importantes reduções nos custos com fatores de produção, mas também poupar o ambiente de um adicional de poluição (Veiga et al., 2012).

Qualquer minhoca pode ser utilizada na vermicompostagem, porém as mais utilizadas e eficientes neste tipo de trabalho são as Eisenia fetida $e$ andrei, conhecidas como minhoca vermelha ou californiana (Sharma et al., 2005).

Segundo Silva et al. (2011), os substratos para produção de minhocas podem afetar a reprodução e taxa de crescimento. O conhecimento do melhor substrato para auxiliar na atividade de criação de minhocas pode ampliar a atividade, visando à produção de húmus de qualidade, que também propicie uma boa reprodução desses anelídeos, disseminando a proposta da vermicompostagem entre os agricultores, como atividade sustentável e rentável.

Nesse cenário a pesquisa objetivou avaliar a reprodução de minhocas Eisenia fetida, em diferentes substratos e verificar o entendimento dos agricultores familiares de três comunidades rurais do municipio de Coxixola-PB sobre a vermicompostagem.

\section{Material e Métodos}

$\mathrm{O}$ experimento foi conduzido nos meses de março a maio de 2017, e conduzido em duas etapas: estudo de percepção com os agricultores de três comunidades rurais do Município de Coxixola, Paraíba, Brasil e ensaio de campo, montado na fazenda experimental do Centro de Desenvolvimento Sustentável do Semiárido (CDSA) da Universidade Federal de Campina Grande (UFCG) Campus, Sumé-PB.

Predomina nos municípios o tipo climático Bsh de Köppen (semiárido quente), com chuvas apresentando uma forte variação na distribuição espacial, temporal e interanual e uma estação de estiagem que pode atingir 11 meses, com precipitação média anual superior a $600 \mathrm{~mm}$ (Sena e Lucena 2014). A temperatura média é de $26^{\circ} \mathrm{C}$, com máxima nos meses de novembro e dezembro e mínima nos meses de julho a agosto. A insolação na região de Sumé corresponde a cerca de 2800 horas luz (Moura, 2002).

A vegetação predominate na região é do tipo caatinga hiperxerófila, com trechos de florestas caducifólias, tendo como sistema de exploração, a agricultura e pecuária de subsistência, devido principalmente as limitações climáticas que não favorecem esses setores (Francisco, 2010). Quanto à pedologia, predominam os Luvissolos e Neossolos, que são solos jovens, pouco desenvolvidos, com horizontes B textural e argila de atividade alta, não hidromórficos (Embrapa, 2006).

\subsection{Percepação dos agricultores quanto a minhocultura}

A área de atuação do estudo de percepção configura-se, uma parte no núcleo das comunidades rurais de São Joãozinho, Matumbo e Campo do Velho, abrangendo as localidades 
que pertence as referidas comunidades. A ferramenta para coleta de dados foi a entrevista, com roteiro semiestruturado, contendo questões abertas e fechadas, para um melhor aproveitamento das informações.

A escolha das comunidades rurais foi devido a maior expressão de produção agrícola de base familiar, segundo dados da Empresa de Assistência Técnica e Extensão Rural (EMATER).Os moradores do sítio Joãozinho são em número de dez famílias que tem como base de renda as tividades da bovinocultura e caprinocultura de leite, além da ovinocultura de corte.

No sitio Matumbo moram 18 familias, cujo perfil financeiro é semelhante à localidade São Joãozinho, já o Campo do Velho é caracterizado como sendo o maior sitio da zona rural de Coxixola-PB, contendo 71 famílias, sua maioria sobrevivendo da criação de caprinos leiteiros, produção de forragem, ovino de corte e gado leiteiro, contudo, outra parte das famílias destes sitios mantém vínculo empregatício com a Prefeitura Municipal (Figura 1).

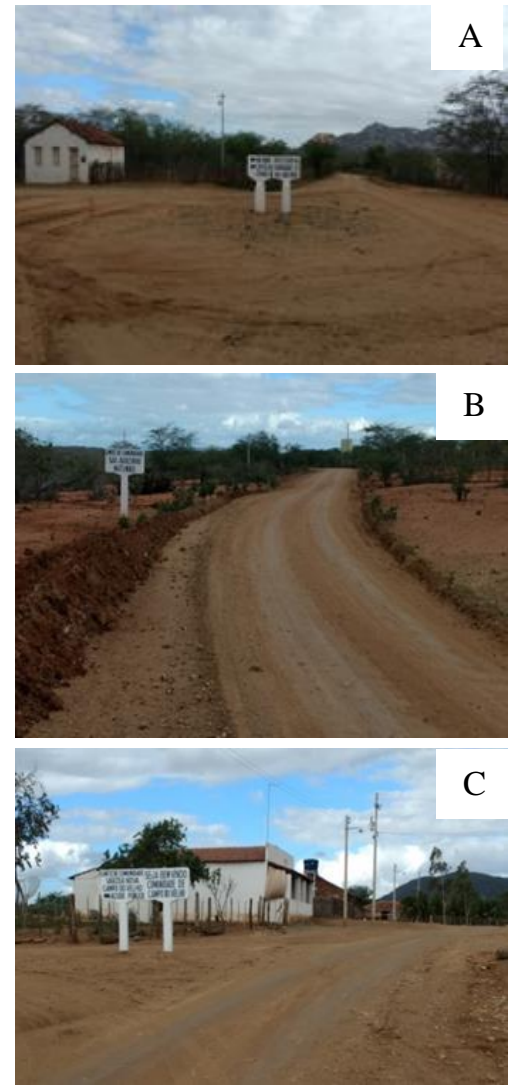

Figura 1 Visão parcial das comunidades estudadas São Joãozinho (A), Matumbo (B) e, Campo do Velho (C) no município de Sumé-PB.

\subsection{Reprodução de minhocas em fontes orgânicas}

$\mathrm{O}$ experimento foi desenvolvido na fazenda experimental do CDSA, campus de Sumé, da Universidade Federal de Capina Grande (UFCG), entre os meses de março a maio de 2017.

O delineamento experimental utilizado foi o inteiramente casualizado (DIC), com 5 tratamentos (estercos bovino (EB), ovino (EO) e caprino (EC) curtidos, composto orgânico (CO) e a mistura proporcional em litros dessas quatro fontes orgânicas (MIX) em 4 repetições, totalizando 20 unidades experimentais.

As unidades experimentais constaram de vasos plásticos pretos com capacidade para seis litros, os quais receberam dois litros do substrato correspondente a cada tratamento e cinco minhocas adultas (cliteladas) da espécie Eisenia fetida, obtidas no minhocário do viveiro de mudas do CDSA e foram dispostos sob uma área cultivada com gliricídias (Gliricidia sepium) para que fosse favorecido um clima agradável às minhocas. Para evitar fuga das minhocas pelas perfurações de descarga do chorume colocou-se no interior dos vasos um forro usando tecino tipo TNT. Os vasos eram trocados de posição duas vezes por semana no sentido horário, evitando possíveis interferências climáticas, já que não se tratava de estufa climatizada, essas trocas eram feitas em blocos, para todas as repetições dos tratamentos passarem por diferentes locais.

Após 60 dias da instalação do experimento, avaliaram-se o número de indivíduos jovens (clitelo subdesenvolvido ou ausente) e adultos (clitelados), o número de casulos, o comprimento e a biomassa de todos os indivíduos e o índice de multiplicação das minhocas (população final/população inicial).

A população de minhocas foi obtida através de contagem manual, com auxílio de pinça laboratorial (Figura 2A), o conteúdo de cada unidade experimental foi colocado sobre um plástico branco onde foram separadas as minhocas jovens, adultas e os casulos presentes no vermicomposto. Os indivíduos coletados em cada unidade experimental foram separados em placas de Petri (Figura 2B) para posteriormente serem pesadas para a obtenção da biomassa de minhocas frescas. Após a pesagem (Figura 2C) as minhocas foram devolvidas ao minhocário. Foi realizado o monitoramento da temperatura dos

Revista Agropecuária Técnica, Areia-PB, v. 39, n. 2, p. 202-210, 2018 
substratos semanalmente, nos períodos da manhã e tarde.
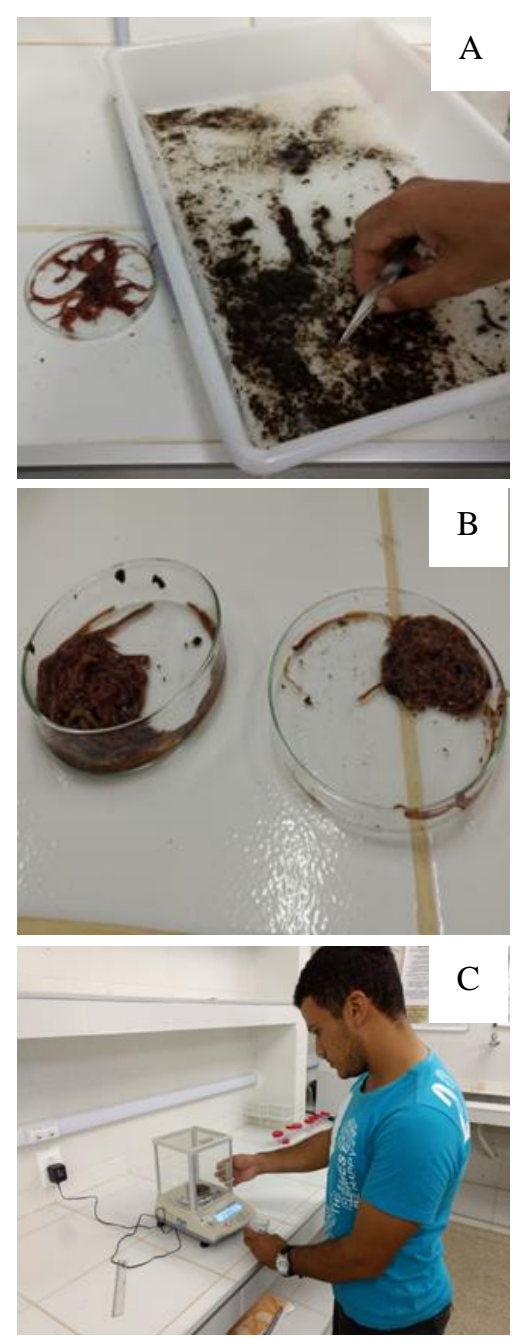

Figura 2 Procedimentos realizados na avaliação das polpulações de minhocas.

\section{Resultados e Discussão}

\subsection{Percepção da minhocultura pelos agricultores}

Questionados sobre a fertilidade do solo, ou seja, a percepção de que o solo indicava que tinha boa qualidade, os agricultores apresentaram conceituações diversas em suas respostas, destacando-se a cor do solo como uma das características mais representativas desse saber empírico. Segundo os agricultores entrevistados, os solos avermelhados e escuros são os mais indicados para o plantio, pois apresentam mais 'sustância' em sua estrutura, proporcionando melhor desenvolvimento às plantas.

O uso da cor do solo como indicador de qualidade tem sido reportado em outros estudos, como os de Reatto e Passos (2016), Audeh et al. (2011) que verificaram que $60 \%$ do agricultores evidenciaram em seus estudos de percepção que solos com cores mais escuras são mais férteis e cores mais claras são mais pobres.

Como fonte de adubação, os estercos ainda são a principal opção dos agricultores nas comunidades visitadas (Figura 3), onde 20 e $30 \%$ dos entrevistados mencionaram outras fontes de adubo, esses mesmos dados poderam ser encontrados quanto uso do composto orgânico, pelo fato dos agriculturores mencionarem outras práticas de conservação como a adubação verde ou os adubos sintéticos (Comunidades São Joãozinho e Matumbo). O uso da adubação orgânica com esterco bovino é uma prática milenar utilizadas por agricultores que tendem a melhorar as condições do solo incorporando fonte de matéria orgânica (Holanda, 1990). A incorporação ao solo de restos vegetais também tem longa tradição na agricultura segundo Sampaio e Oliveira (2005).

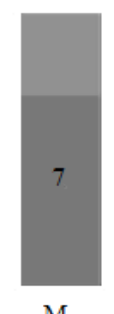

$\mathrm{M}$

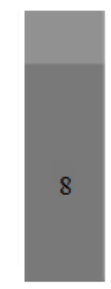

SJ

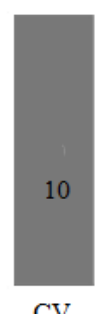

CV
SIM NÃO

Figura 3 Uso de estercos pelos entrevistados. *Sítio Matumbo (M); Sítio São Joãozinho (SJ); Sítio Campo do Velho (CV)

Quanto ao uso do composto orgânico pelos agricultores, esses falaram que não utilizavam esta técnica de adubação e melhoria das condições do solo em suas atividades, apenas 30 e $20 \%$ nos sítios Matumbo e São Joãozinho respectivamente os agricultores.

Em outros ambientes a prática do uso do composto orgânico já é rotineira, Travassos e Souza, (2011) trabalhando com percepção, constatou que a prática da compostagem está pouco presente no meio rural, sendo mais presente a pratica da adubação orgânica com estercos em hortas e pequenas lavoura.

A presente pesquisa expressa o desconhecimento dos agricultores quanto às 
vantagens do uso das fontes de adubo orgânico e da compostagem, apresentando a ausência de conceitos sobre agroecologia e indicando a necessidade de ações voltadas para adoção de políticas públicas que visem suprir essa carência dos agricultores familiares coxixolenses.

É importante considerar que a característica essencial da agroecologia é a utilização de técnicas e práticas agrícolas para uma produção sustentável, como modelo voltado para a vida coletiva, visando questões básicas de sobrevivência. Como cita Leff (2002) a agroecologia propõe o uso da terra de forma que não comprometa o ambiente, onde a agricultura é vista como um sistema vivo e complexo e tem como uma de suas bases filosóficas o Holismo, representado por uma visão do todo, interessando aos produtores não só a produção efetivamente, mas também de toda a comunidade e suas necessidades, prevendo a harmonização da natureza, utilizando-a de forma racional, aliando conservação da natureza à sua exploração para o sustento da comunidade.

Quanto ao uso de minhocas na produção agrícola, $100 \%$ dos entrevistados disseram desconhecer e não fazer uso dessa prática. Apesar das vantagens da vermicompostagem, esta ainda é pouco utilizada pelos agricultores, seja por falta da disseminação ou por estes acreditarem que seja uma técnica cara e complexa e por não terem acesso às minhocas.

Em pesquisa com agricultores sobre a atividade da vermicompostagem, Souza (2014) verificou que apesar de compreender a importância das minhocas para a qualidade do solo, a maioria dos agricultores da Zona da Mata mineira não conhecia um minhocário.

Dentre os representantes da macrofauna do solo, as minhocas tem atuação relevante, sendo conhecidas como "engenheiros do ecossistema", por serem capazes de formar galerias e túneis, estruturando o solo de forma a facilitar que as raízes das plantas penetrem com mais facilidade em busca de água e nutrientes, possibilitando também que a água da chuva e o ar possam atingir camadas mais profundas (Velásquez et al., 2010). As minhocas influenciam na ciclagem de nutrientes, especialmente sobre a decomposição da matéria orgânica do solo, que é proveniente de restos de plantas e folhas que caem ao solo (Zortéa et al., 2012).
$\mathrm{Na}$ presente pesquisa, os entrevistados remeteram-se à presença das minhocas no solo como uma ameaça às culturas agrícolas, colocando-as como uma das causas de danos à lavoura, argumentando que as mesmas se alimentam dos cultivos. Essas colocações foram mais particularmente citadas por agricultores da localidade São Joãozinho.

Como contraponto, os agricultores das comunidades Campo do Velho e Matumbo trouxeram nas respostas noções claras de como as minhocas podem auxiliar na manutenção do solo (adubam a terra, fofa a terra, deixam a terra forte), o que leva a perceber que estes estão mais familiarizados com o entendimento dos efeitos das minhocas no solo, mesmo não fazendo uso da vermicompostagem, talvez por conta da mídia e outras fontes de informação (Figura 4).

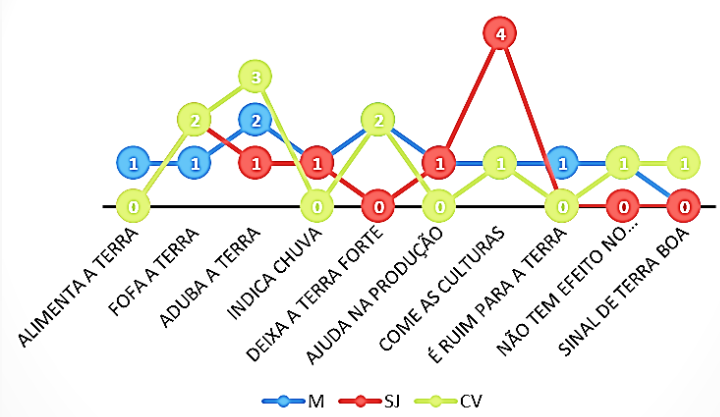

Figura 4 Entendimento dos entrevistados sobre a presença das minhocas. *Sítio Matumbo (M); Sítio São Joãozinho (SJ); Sítio Campo do Velho (CV).

Relativo à percepção dos agricultores quanto ao interesse pela criação das minhocas e possibilidades de agregar valor a sua produção, os mesmos demonstraram em suas respostas ainda muita desconfiança, embora os agricultores das comunidades $\mathrm{M}$ e $\mathrm{CV}$ tenham se mostrados mais interessados na proposta (Figura 5).

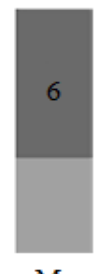

$\mathrm{M}$

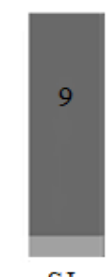

SJ

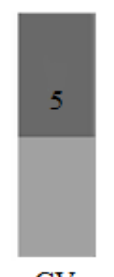

CV

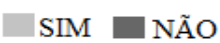

Figura 5 Percepção dos agricultores sobre o húmus de minhoca como possibilidade de agregar valor a produção. *Sítio Matumbo (M); Sítio São Joãozinho (SJ); Sítio Campo do Velho (CV) 
Reprodução de minhocas em substratos orgânicos e a percepção de agricultores familiares sobre ...

Farias et al.

\subsection{Experimento de campo}

Todos os tratamentos proporcionaram condições para a reprodução e desenvolvimento das minhocas. O maior número foi verificado no substrato Mix, obtendo-se o total de 414 indivíduos, resultado superior ao encontrado por Steffen (2008) no tratamento constituído por casca de arroz inteira obtendo-se o total de 187 indivíduos (Tabela 1).

Tabela 1 Número total de minhocas (jovens e adultas), número de casulos, volume final do vermicomposto e índice de multiplicação obtidos nos tratamentos à base de adubos orgânicos

\begin{tabular}{ccccccc}
\hline & SUBSTRATO & $\begin{array}{c}\mathrm{N}^{\circ} \text { inicial } \\
\text { (minhoca/vaso) }\end{array}$ & $\begin{array}{c}\mathrm{N}^{\circ} \text { Final } \\
\text { (Adulto- Jovem) }\end{array}$ & $\mathrm{IM}^{*}$ & $\mathrm{~N}^{\circ}$ Casulos \\
\cline { 2 - 6 } $\mathrm{I}$ & $\mathrm{EB}$ & 5 & 343 & 68,6 & 194 & $\mathrm{~F}$ \\
$\mathrm{~N}$ & $\mathrm{EC}$ & 5 & 20 & 4,0 & 54 & $\mathrm{I}$ \\
$\mathrm{I}$ & $\mathrm{EO}$ & 5 & 52 & 10,4 & 30 & $\mathrm{~N}$ \\
$\mathrm{C}$ & $\mathrm{CP}$ & 5 & 20 & 4,0 & 3 & $\mathrm{~A}$ \\
$\mathrm{I}$ & $\mathrm{MIX}$ & 5 & 414 & 82,8 & 160 & $\mathrm{~L}$ \\
$\mathrm{O}$ & & & & & & \\
\hline
\end{tabular}

O maior número de casulos foi obtido no tratamento constituído pelo esterco bovino, no qual foram encontrados 194 casulos a partir da inoculação de apenas cinco matrizes, correspondendo a aproximadamente 65 vezes mais casulos do que no tratamento composto, onde foram observados apenas 3 casulos, em um período de multiplicação de apenas 60 dias (Figura 6).

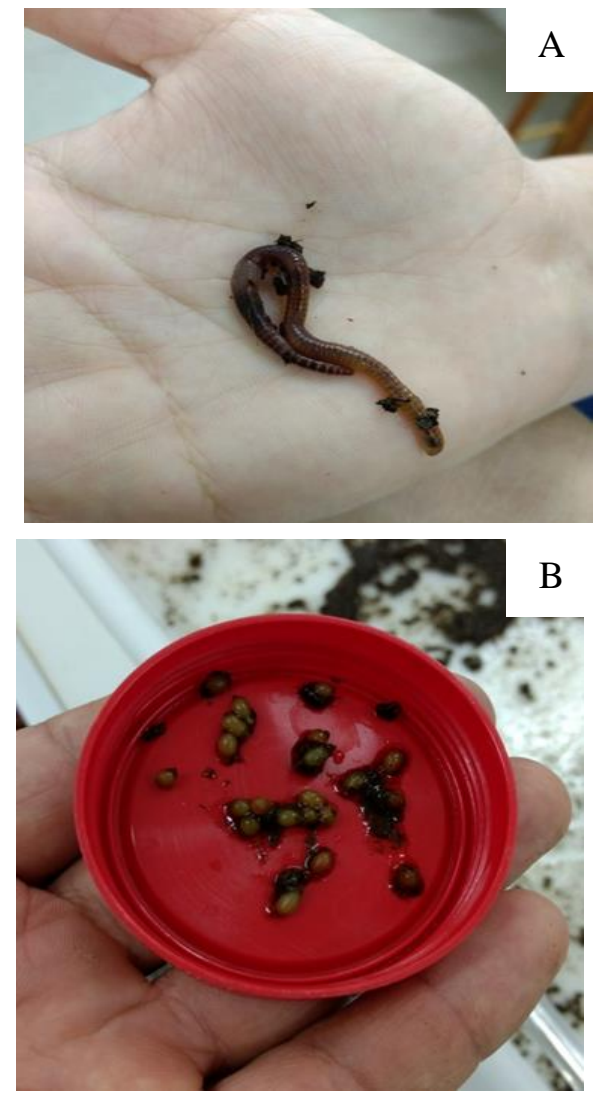

Figura 6 Minhoca adulta clitelada (A) e casulos (B).
Os substratos foram eficientes para a criação das minhocas Eisenia fetida, porém o tratamento $\mathrm{EB}$, que apresentou uma relação $\mathrm{C} / \mathrm{N}$ mais elevada disponibilizou mais alimentos para a decomposição e produção do vermicomposto (Tabela 2). Situação diferente foi observada por Alencar et al. (2016) que verificaram maior reprodução de minhocas $E$. fetida em substratos que apresentam uma relação $\mathrm{C} / \mathrm{N}$ mais baixa.

Tabela 2 Caracterização dos estercos e do composto utilizados na pesquisa

\begin{tabular}{lccccc}
\hline Estercos & $\mathbf{C}$ & $\mathbf{N}$ & $\mathbf{P}$ & $\mathbf{K}$ & $\mathbf{C} / \mathbf{N}$ \\
& ---------- & g kg-1 \\
\hline Caprino & 192,52 & 11,90 & 2,51 & 9,85 & 16 \\
Bovino & 257,60 & 14,80 & 3,70 & 6,90 & 17 \\
Ovino & 347,00 & 18,00 & 1,36 & 4,24 & 19 \\
Composto & 492,70 & 40,90 & 2,05 & 7,93 & 12 \\
Mix & 322,46 & 24,40 & 2,40 & 7,20 & 13 \\
\hline C = Carbono; N = Nitrogênio; P = Fósforo; K = Potássio; \\
C/N = Relação Carbono/Nitrogênio.
\end{tabular}

Quanto ao índice de multiplicação, parâmetro que avalia a capacidade reprodutiva das matrizes em determinado ambiente (Alencar et al., 2016), foi verificada que o tratamento MIX apresentou o maior valor na reprodução $(82,8)$, seguido do tratamento EB.

A variação da temperatura dos substratos durante o período de vermicompostagem foi monitorada com termômetro tipo INCOTERM L 016/12. Na (Figura 7) é possível observar a evolução da temperatura nos diferentes tratamentos, a temperatura inicial teve um decréscimo acentuado na primeira semana, mantendo-se uniforme para o CP e apresentando oscilações para os demais substratos orgânicos

Revista Agropecuária Técnica, Areia-PB, v. 39, n. 2, p. 202-210, 2018

DOI: https://doi.org/ 10.25066/agrotec.v39i2.39484 
estudados, sendo mais expressiva no EO e com maior queda para o MIX.

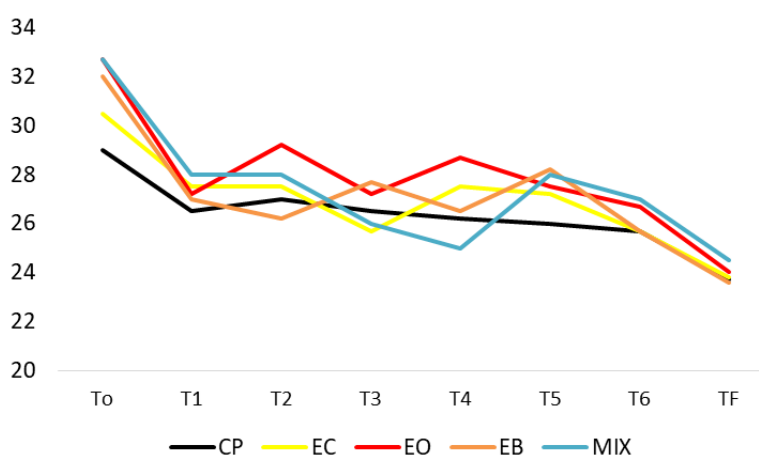

Figura 7 Variação da temperatura das diferentes fontes orgânicas, durante a vermicompostagem (média de quatro repetições). *Composto (CP); Esterco Caprino (EC); Esterco Ovino (EO); Esterco Bovino (EB); Mistura de Estercos (MIX).

As quedas repentinas da temperatura foram ocasionadas possivelmente em função das chuvas dos dias 30 de Março, 21 de Abril, conforme dados da AESA (2017) apresentado na (Figura 8).

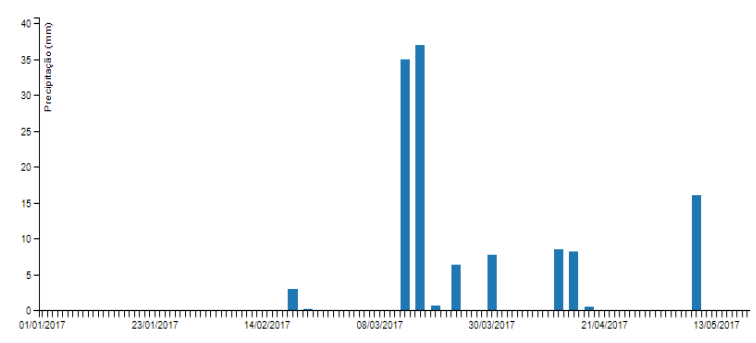

Figura 8 Dados pluviométricos dos meses de Março e Abril. Fonte: AESA (2017).

Analisando a (Tabela 3) observa-se que para o número de casulos não houve diferença estatística entre os tratamentos EB e Mix, embora o EB tenham superado estatisticamente os demais tratamentos, seguido pelo MIX, que também superou os demais tratamentos. Os tratamentos EB e Mix não diferiram estatisticamente para as demais variáveis, com esseção para a massa de minhocas adultas.

Tabela 3 Número total de minhocas (jovens e adultas), número de casulos, tamanho e biomassa de minhocas (jovens e adultas), obtidos nos tratamentos à base de adubos orgânicos Média de quatro repetições

\begin{tabular}{lccccccc}
\hline \multirow{2}{*}{ Tratamentos Números } & \multicolumn{3}{c}{ Tamanho } & \multicolumn{2}{c}{ Massa } \\
\cline { 2 - 7 } & Casulos & Adultos & Jovens & Adulto & Jovem & Adulto & Jovem \\
\hline \multirow{2}{*}{ Composto } & $0,75 \mathrm{c}$ & $5,0 \mathrm{~b}$ & $0,0 \mathrm{~b}$ & $8,75 \mathrm{ab}$ & $0,0 \mathrm{~b}$ & $1,80 \mathrm{c}$ & $0,0 \mathrm{~b}$ \\
Est. Bovino & $48,0 \mathrm{a}$ & $86,0 \mathrm{a}$ & $150,0 \mathrm{a}$ & $12,00 \mathrm{a}$ & $3,50 \mathrm{a}$ & $27,76 \mathrm{~b}$ & $16,15 \mathrm{a}$ \\
Est.Caprino & $13,0 \mathrm{bc}$ & $5,0 \mathrm{~b}$ & $0,0 \mathrm{~b}$ & $9,50 \mathrm{ab}$ & $0,0 \mathrm{~b}$ & $3,09 \mathrm{c}$ & $0,0 \mathrm{~b}$ \\
Est. Ovino & $7,0 \mathrm{bc}$ & $3,0 \mathrm{~b}$ & $10,2 \mathrm{~b}$ & $6,78 \mathrm{~b}$ & $0,0 \mathrm{~b}$ & $1,82 \mathrm{c}$ & $0,0 \mathrm{~b}$ \\
Mix & $40,0 \mathrm{ab}$ & $103,0 \mathrm{a}$ & $128,0 \mathrm{a}$ & $12,00 \mathrm{a}$ & $3,63 \mathrm{a}$ & $37,54 \mathrm{a}$ & $12,02 \mathrm{a}$ \\
\hline $\mathrm{CV}^{* *}$ & 71,65 & 46,82 & 64,50 & 30,82 & 57,90 & 24,01 & 36,61 \\
\hline
\end{tabular}

*Médias seguidas da mesma letra na coluna não diferem estre si pelo teste de Tukey, a $5 \%$ de probabilidade.

** Coeficiente de variação.

Quanto ao número final de minhocas, observou-se diferença significativa entre os tratamentos. Resultado diferente foram encontrados por Alencar et al. (2016) que não observaram maior reprodução de minhocas $E$. fetida no esterco bovino, apontando que os resultados de pesquisa não são unânimes quanto à inclusão do esterco bovino curtido na produção de minhocas jovens, adultas, cocons e taxa de multiplicação.

Antoniolli et al. (2009) encontraram uma população final de 44 minhocas e Steffen et al. (2010) obtiveram 205 (inicial de 6), respectivamente, demonstrando que a composição do esterco, o meio ambiente (temperatura e umidade) influenciaram os resultados.

Já Loh et al. (2005) concluíram em pesquisa envolvendo minhoca da espécie E. fetida e diferentes estercos, que o esterco de bovinos superou o esterco caprino como substrato para o desenvolvimento e reprodução das minhocas e que a biomassa das minhocas e o desempenho reprodutivo, em termos de número de anelídeos após cinco semanas de experimento.

No geral, possivelmente, os resultados observados estejam relacionados à adição de nitrogênio ao meio, oriundo da ração que são fornecidas aos animais e da presença das fezes, as quais foram fundamentais para as manutenções da microbiota presente no trato digestivo das 
minhocas, atuando na transformação dos resíduos orgânicos.

\section{Conclusão}

Os agricultores desconhecem e não fazem uso da minhocultura, e possuem visão distorcida da presença destes representantes da macrofauna do solo. As minhocas da espécie Eisenia fétida tem reprodução elevada em estercos orgânicos, sendo indicado o uso da mistura de estercos e composto, como também de esterco bovino.

\section{Referências}

Alencar, A. P.; Netto, A. J.; Nogueira, B. D. Efeito de substratos na produção e multiplicação de Eisenia fetida Savigny (1826). Acta Kariri Pesquisa e Desesenvolvimento, v.1, n.1, p.2128 , 2016. http://actakariri.crato.ifce.edu.br/index.php/actakariri/artic $\underline{\text { le/view/3/4 }}$

Antoniolli, Z. A.; Steffen, G.P. K.; Steffen, R. B. Utilização de casca de arroz e esterco bovino como substrato para a multiplicação de Eisenia fetida Savigny (1826). Ciência Agrotecnologia, v. 33, n. 3, p. 824-830, 2009. http://dx.doi.org/10.1590/S1413-70542009000300022

Audeh, S.; Lima, A. C. R.; Cardoso, I. M.; Casalinho, H. D.; Jucksch, J. Qualidade do solo: uma visão etnopedológica em propriedades agrícolas familiares produtoras de fumo orgânico. Revista Brasileira de Agroecologia. v.6, n.3, p.34-48, 2011. http://orgprints.org/22989/1/Audeh_Qualidade.pdf

Mucelin, C. A.; Bellini, M. Garbage and perceptible environmental impacts in urban ecosystem. Sociedade \& Natureza, v.20, n.1, p.111-124, 2008. http://dx.doi.org/10.1590/S1982$\underline{45132008000100008}$

Costa, M.; Miranda, F.; Veloso, A. A vermicompostagem como via para a reciclagem de nutrientes na exploração agrícola: efeito na produção da alface em MPB. Colóquio Nacional de Produção Animal Biológica, 1. $2011 . \quad$ http://www.drapn.minagricultura.pt/drapn/conteudos/laboratorio/Vermicomprev.pdf

Darolt, M. R. Agricultura orgânica: inventando o futuro. IAPAR, Londrina. 2002. 250p.

EMBRAPA. Centro Nacional de Pesquisa de Solos. Sistema Brasileiro de Classificação de

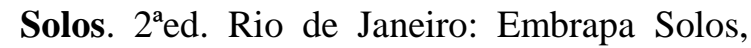
2006.

Francisco, P. R. M. Classificação e mapeamento das terras para mecanização do Estado da Paraíba utilizando sistemas de informações geográficas. Dissertação (Mestrado em Manejo de Solo e Água). Centro de Ciências Agrárias, Universidade Federal da Paraíba, Areia, 2010.

Lago, A. L.; Elis, V. R.; Giacheti, H. L. Aplicação integrada de métodos geofísicos em uma área de disposição de resíduos sólidos urbanos em Bauru-SP. Revista Brasileira de Geofísica, v. 24, n.3, p.357-374, 2006. http://www.scielo.br/scielo.php?script=sci_arttext\&pid=S 0102-261X2006000300005

Leff, E. Agroecologia e saber ambiental. Agroecologia e Desenvolvimento Rural Sustentável, v.3, n.1, p.36-51, 2002. http://taquari.emater.tche.br/docs/agroeco/revista/ano3_n 1/revista_agroecologia_ano3_num1_parte08_artigo.pdf

Loh, T. C.; Lee, Y. C.; Liang, J. B.; Tan, D. Vermicomposting of cattle and goat manures by Eisenia fetida and their growth and reproduction performance. Bioresource Technology, v.96, n.1, p.111-114. 2005. https://doi.org/10.1016/j.biortech.2003.03.001

Moura, C. S. Vulnerabilidades das Terras Agrícolas, Degradação Ambiental e Riscos e Desastres ENOS no Município de Sumé-PB. 2002. 155p. Dissertação (Mestrado em Engenharia Agrícola), Universidade Federal de Campina Grande, Campina Grande, 2002.

Penteado, S. R. Adubação na agricultura ecológica: cálculo e recomendação numa abordagem simplificada. $2^{\mathrm{a}}$ ed. Campinas: Edição do autor, 2009. 168p.

Reatto, A; Passos, R. F. Soil as an integrating factor between environmental components and agricultural production. Pesquisa Agropecuária Brasileira, v.51, n.9, p.xi-xix, $2016 . \quad$ http://dx.doi.org/10.1590/S0100204X2016000900iii

Sampaio, E. V. S. B.; Oliveira, N. M. B. Aproveitamento da macrófita aquática Egeria densa Planchon como adubo orgânico. Planta Daninha, v.23, n.2, p.169-174, 2005. http://dx.doi.org/10.1590/S0100-83582005000200001

Sena, J. P. de O.; Lucena, D. B. Caracterização da precipitação na microrregião do Cariri Paraibano por meio da técnica dos quantis. 
Revista Brasileira de Geografia Física, v.7, n.5, p.1-9, 2014. https://periodicos.ufpe.br/revistas/rbgfe/article/view/2333 99

Sharma, S.; Pradhan, K.; Satya, S.; Vasudevan, P. Potentiality of earthworms for waste management and in other uses - a review. The Journal of American Science, v.1, n.1, p.4-16. 2005. http://dx.doi.org/10.7537/marsjas010105.02

Silva, R. F.; Guimarães, M. F.; Aquino, A. M.; Mercante, F. M. Análise conjunta de atributos físicos e biológicos do solo sob sistema de integração lavoura-pecuária. Pesquisa Agropecuária Brasileira, v.46, n.10, p.12771283, 2011. http://dx.doi.org/10.1590/S0100204X2011001000023

Souza, M. E. P. de. Vermicompostagem enriquecida com pós de rochas e sua utilização em sistemas agroecológicos. UFV: Viçosa. 2014.

Steffen, G. P. K. Substratos à base de casca de arroz e esterco bovino para a multiplicação de minhocas e produção de mudas de alface, tomateiro e boca-de-leão. 2008. Santa Maria, RS, 97 f. Dissertação (Mestrado em Ciência do Solo) - Universidade Federal de Santa Maria, UFSM.

Steffen, G. P. K.; Antniolli, Z. I.; Steffen, R. B.; Machado, R. G. Casca de aroz e esterco bovino como substratos para a multiplicação de minhocas e produção de mudas de tomate e alface. Acta Zoológica Mexicana, v.26, suplemento 2, p.333-343, 2010. http://www.scielo.org.mx/pdf/azm/v26nspe2/v26nspe2a2 5.pdf

Travassos, I. S.; Souza, B. I de. Solos e desertificação no sertão Paraibano. Cadernos do Logepa, v.6, n.2, p.101-114, 2011, http://www.periodicos.ufpb.br/index.php/logepa/article/vi ewFile/10862/6956

Veiga, M. da; Durigon, L.; Pandolfo, C. M.; Balbinot Junior, A. A. Atributos de solo e de plantas afetados pelo manejo da pastagem anual de inverno em sistema de integração lavourapecuária. Ciência Rural, v.42, n.3, p.444-450, 2012.

http://www.scielo.br/pdf/cr/v42n3/a6212cr2239.pdf

Velásquez, J.; Tejera, R.; Hernando, A.; Núñes, M. V. Environmental diagnosis: integrating biodiversity conservation in management of Natura 2000 forest spaces. Journal for Nature Conservation, v.18, n.4, p.309-317, 2010. https://doi.org/10.1016/j.jnc.2010.01.004

Zortéa, T.; Machado, J. S.; Bartz, M. C.; Baretta, D. A Importância das minhocas em sistemas agricultáveis. SB Rural. n.99. 2012. http://www.ceo.udesc.br/arquivos/id submenu/285/cader no_udesc_099.pdf 